\title{
Clustered Pain Procedures in Skin-to-Skin Contact (SSC) Position for Full Term Newborns
}

\author{
Raouth R. Kostandy ${ }^{1}$, Susan M. Ludington-Hoe ${ }^{2}$ \\ ${ }^{1}$ Cleveland State University School of Nursing, Cleveland, OH, USA \\ ${ }^{2}$ Bolton School of Nursing, Case Western Reserve University, Cleveland, OH, USA \\ Email: ^rrkostandy@yahoo.com, Susan.ludington@case.edu
}

How to cite this paper: Kostandy, R.R. and Ludington-Hoe, S.M. (2017) Clustered Pain Procedures in Skin-to-Skin Contact (SSC) Position for Full Term Newborns. World Journal of Neuroscience, 7, 38-47. https://doi.org/10.4236/wjns.2017.71004

Received: November 22, 2016

Accepted: December 27, 2016

Published: December 30, 2016

Copyright $\odot 2017$ by authors and Scientific Research Publishing Inc. This work is licensed under the Creative Commons Attribution International License (CC BY 4.0).

http://creativecommons.org/licenses/by/4.0/

\begin{abstract}
As a part of their routine care, full term newborns face many painful procedures immediately after birth and during the first couple days of life. Skin-toSkin Contact (SSC) has been recommended as a non-pharmacological pain management intervention in newborns. However, the use of SSC in labor and delivery rooms as well as in postnatal units and nurseries is limited due to the discomfort that the nurses and phlebotomists themselves experience during positioning the newborns and themselves to complete these routine procedures. The objective of this paper is to describe a step-by-step procedure that was developed and used in a randomized clinical trial to manage newborns pain during clustered pain procedures. The procedure worked well and no complaints of discomfort were reported by the nurses during the study.
\end{abstract}

\section{Keywords}

Full Tern Newborns, Clustered Painful Procedures, Skin-to-Skin Contact (SSC)

\section{Introduction}

The American Academy of Pediatrics [1] [2] and the Canadian Pediatric Society [3] have recommended that skin-to-skin contact (SSC) be used to minimize procedural pain in full term and preterm newborns. Amelioration of neonatal pain is needed to prevent the short- and long-term adverse effects of untreated repeated pain in the neonatal period [4] [5] [6]. Repeated unrelieved procedural pain is related to life threatening physiological [7] [8] and behavioral outcomes [9], including long-term heightened pain or hyperalgesia [10] [11], and increased stress sensitivity [12]. Sources of repeated pain in the neonatal period are the invasive procedures needed to obtain bilirubin and glucose samples, testing 
blood for phenylketonuria, and administration of Vitamin K and Hepatitis B injections prior to discharge in healthy full term newborns. SSC has been confirmed as an effective non-pharmacologic pain reduction intervention when provided by the mother or father [13] [14], and when given alone [15] [16] [17] or in combination with breastfeeding [18], sucrose [19], and rocking [20]. SSC relieves pain from heel-stick [21] [22] [23], injection [15] [16] [24], or venipuncture [25]. A Cochrane analysis of randomized trials of SSC's pain reduction effects in preterm newborns showed that it is highly effective in reducing the pain associated with painful procedures [26]. Though these numerous studies have been conducted, many nurses still do not practice SSC to reduce pain in clinical settings [27] [28] [29] [30]. Reasons for the under-utilization of SSC are unfamiliarity with using this non-pharmacological intervention to reduce procedural pain [30] and anticipated discomfort by nurses and phlebotomists when conducting heel sticks and injections during SSC [28].

The discomfort that nurses and phlebotomists experience is due to the lack of using an ergonomic position that maintains the equilibrium of the body and the gravity line [31]. Usually nurses and/or phlebotomists need to bend over, for as long as needed, when doing lances and injections in SSC. Thus, the ergonomic position is compromised. Trunk movement and trunk rotation were reported as leading causes of discomfort and pain in nurses. In addition, nurses viewed patient care activities that require long time exposure to unwieldy positions as "high physical effort" [32]. Therefore, nurses under-utilize SSC during these painful procedures. Nurses are encouraged to use ergonomic science to decrease physical discomfort and low back injuries. Therefore, the purpose of the manuscript is to describe a step-by-step procedure we developed and which worked well (no discomfort in the health care provider) in a recently completed randomized controlled trial of SSC to reduce newborn pain during clustered invasive procedures. The procedure worked so well in eliminating nurse discomfort that we hope others will use it so that SSC will be more widely used as an effective non-pharmacologic nursing intervention. The procedure that is being proposed has been designed to satisfy two needs: integration of SSC as a pain reduction intervention in newborns and prevention of discomfort in the health care provider when drawing bloods and injecting medications during SSC.

\section{The Procedure}

The following is a step-by-step procedure with rationale that has allowed safe administration SSC during clustered administration of PKU, bilirubin, and Hepatitis B procedures in healthy term newborns. The step-by-step procedure below is for heel stick followed by injection. We recommend conducting the heel stick and heel squeezing procedures first because infants are less likely to cry with these procedures than with injections. Conducting the most painful procedure last is believed to facilitate recovery from pain as the infant rests undisturbed in SSC during recovery.

1. Confirm with mother that she is willing to hold her newborn skin-to-skin 
during the painful procedure. Most mothers desire to be involved in their newborns' pain care and nurses should provide proper information and education to mothers to achieve this goal [33] [34].

2. Adjust the head of the mother's bed to an incline of 60 degrees because mothers report more comfort holding the infant when 60 degrees upright rather than less. Also, nurses have expressed better comfort when the infant is at a 60 degree incline rather than $30-40$.

3. Raise the level of the bed until the infant in skin-to-skin is at a comfortable height equal to the nurse's chest so the nurse will not be bent over.

4. Place the newborn skin-to-skin, upright, and chest-to chest with the mother (Figure 1).

5. Cover the newborn with a receiving blanket and the mother's bed sheet to prevent heat loss across the newborn's back.

6. Place a warm pad to the heel to facilitate blood flow when doing heel sticks [35] (Figure 2). Cover the heel with the blankets.

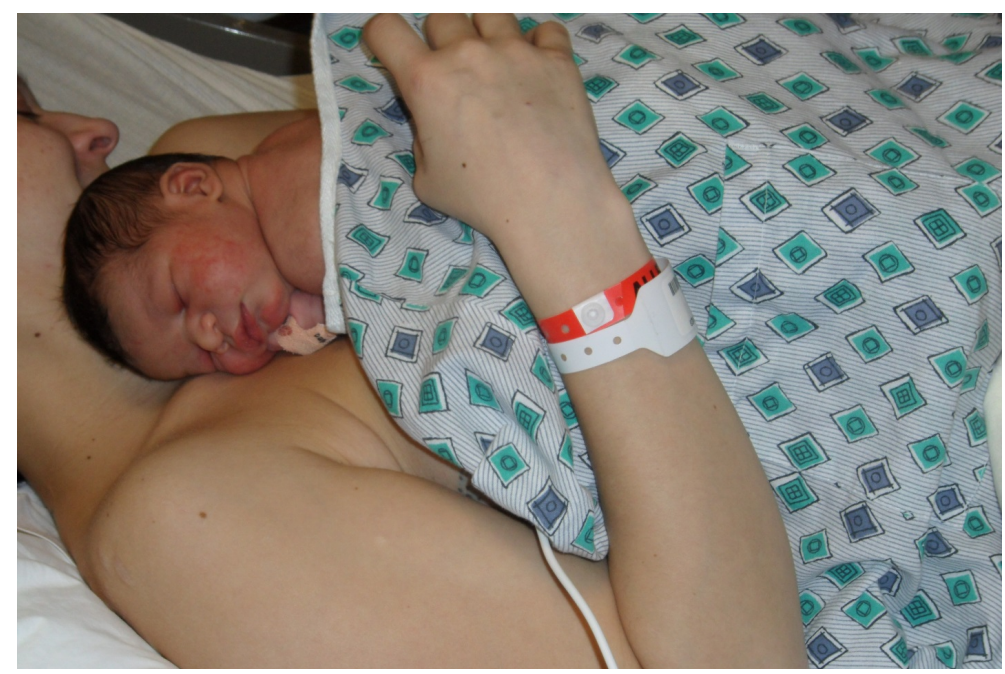

Figure 1. SSC position before the procedures.

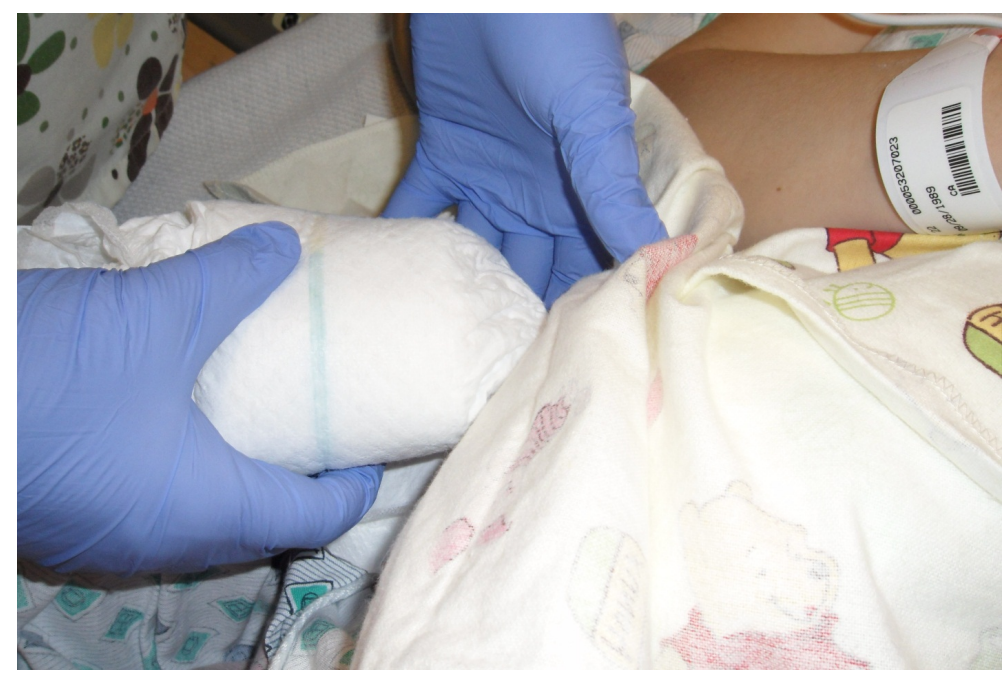

Figure 2. Place a warm pad to the heel. 
7. Leave the mother-newborn dyad skin-to-skin for 10-15 minutes for calming. Ten-to-fifteen minutes is sufficient to help the dyad nest and relax [16] [36].

8. Prepare the equipment on the tray table or on the side of the mother's bed.

9. Move the newborn into an oblique position (Head at the top of one breast and body beneath the opposite breast) so access to the heel or thigh is facilitated. The newborn will still be skin-to-skin, but not chest-to-chest.

10. Extract the newborn's foot from beneath the blankets.

11. Remove the warming pad from the heel.

12. Hold the foot within your hand to allow gravity to facilitate blood flow into the foot (Figure 3).

13. Swab the lower lateral area of the heel facing the nurse with an alcohol pad.

14. Use a spring-loaded lancet to stick the heel (Figure 4), put the lancet on the tray or the equipment area on the mother's bed.

15. Hold the PKU circle sheet at the lanced site and start to gently squeeze the heel to obtain blood to cover the five test circles (Figure 5).

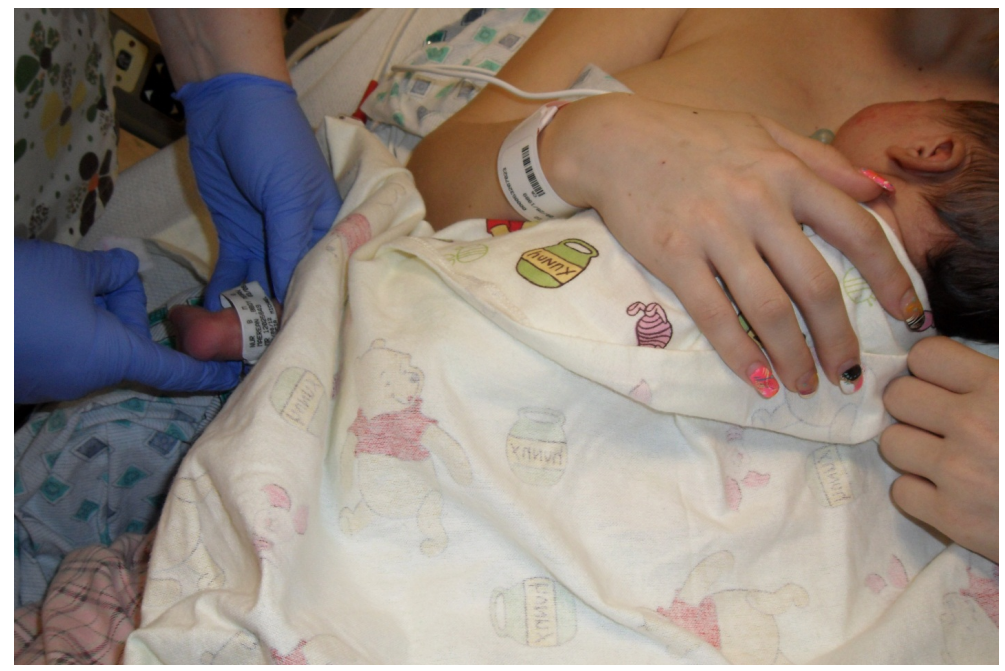

Figure 3. Foot positioned for the heel lancing.

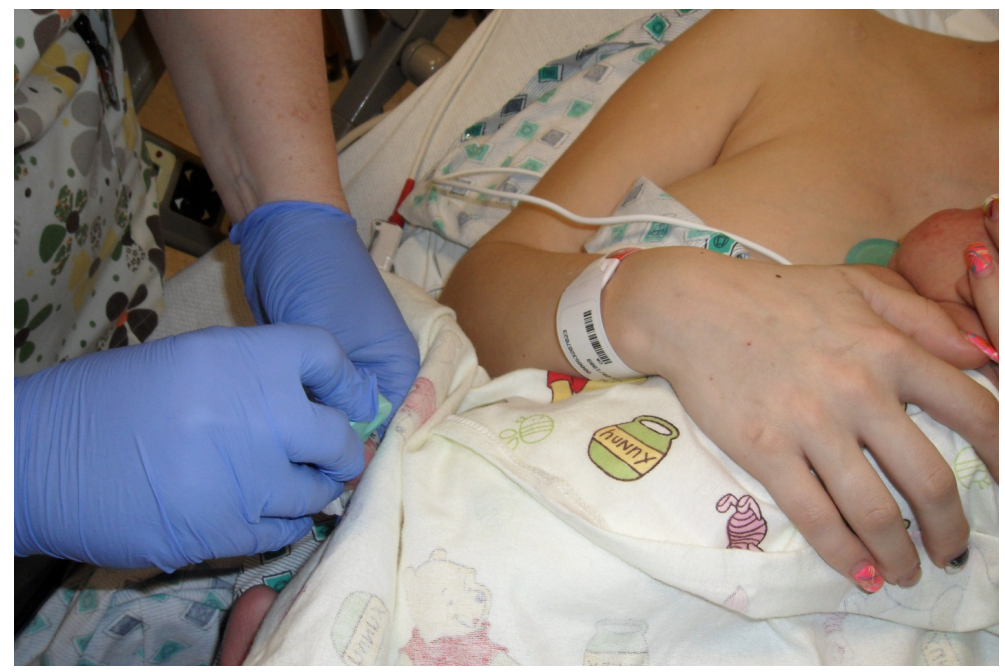

Figure 4. Heel lancing. 


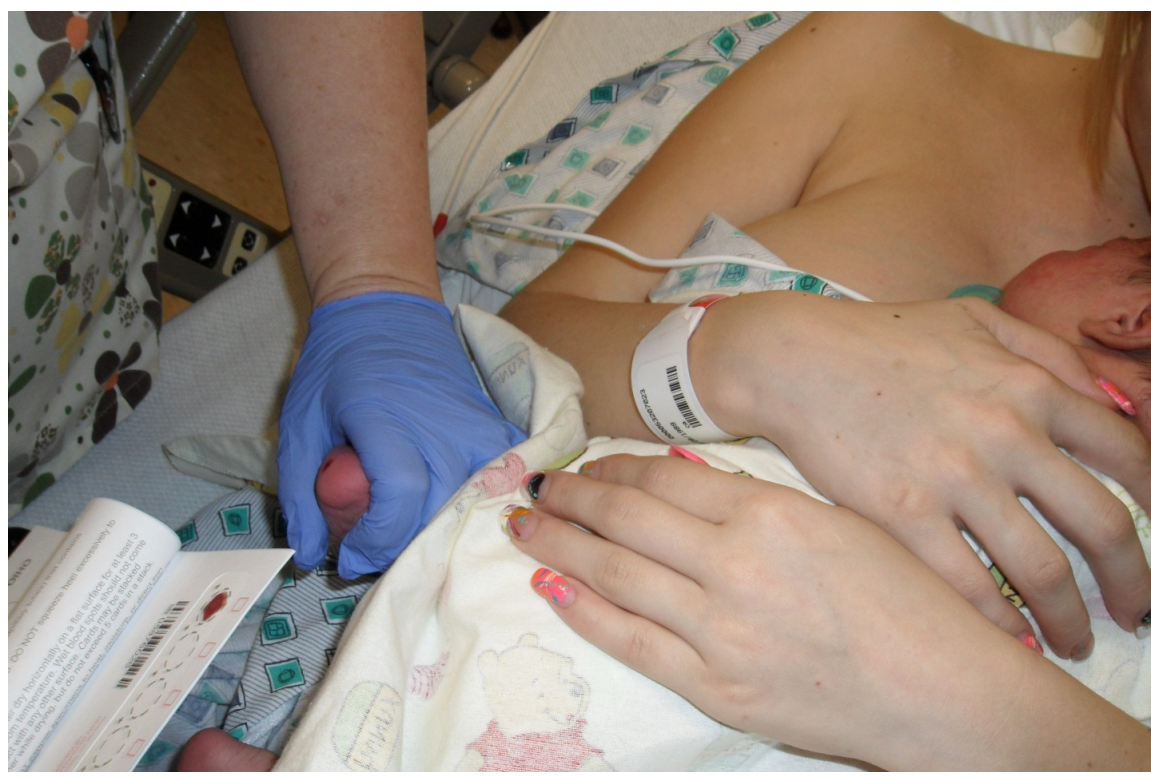

Figure 5. PKU blood collection.

16. Observe newborn's response. Often newborns do not cry with the heel stick, but squeezing is more painful, so try to minimize the squeezing as much as possible. Be sure that newborn is held securely and is up against the mother's skin. Reassure the mother that holding her newborn during the procedure is really one of the best ways (the best way is to keep the newborn skin-to-skin and breastfeed with the stick and squeezes [37]) she can help her newborn tolerate the procedure with less pain. If the infant is not crying, point this out to the mother and tell her "Your baby is not even crying. That is how well you are helping your baby tolerate these painful procedures".

17. After the heel stick test is completed, cover the lanced site with gauze or band aid (Figure 6).

18. Extract and expose the newborn upper thigh from beneath the blanket with carefully making sure that the rest of the newborn's body is still covered.

19. Position the thigh to face the nurse.

20. Swab the appropriate site with alcohol pad.

21. Hold the lateral thigh muscle between the thumb and fingers.

22. Inject the vaccine/medication (Figure 7).

23. If needed, place a band aid over the injection site.

24. Place the leg back and readjust the newborn position to the skin-to-skin, chest-to-chest position making sure that the newborn is covered. Return the mother's bed to its original level.

25. Assess and document the newborn's pain level during the heel stick, during the squeeze(s), and then during the injection using the institution's standardized pain scoring system.

\section{Clinical Implications}

The procedure described above is easy to perform according to nurses who in- 


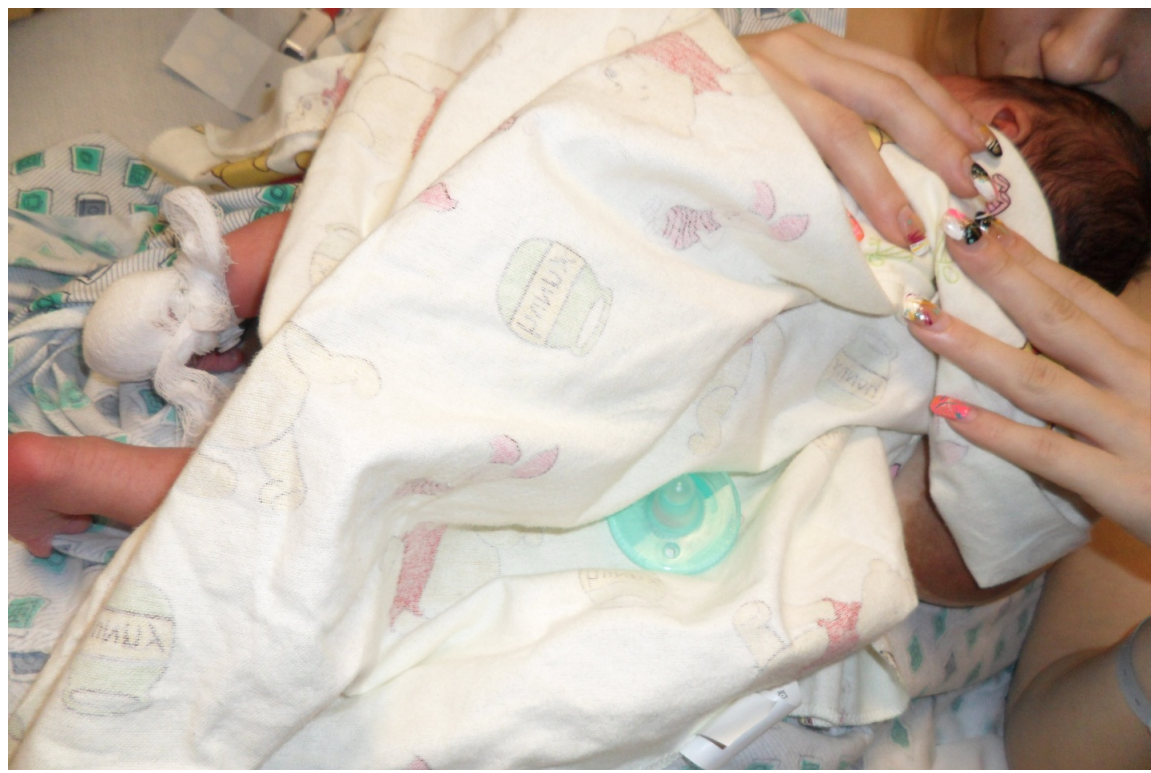

Figure 6. Cover the heel after blood collection completion.

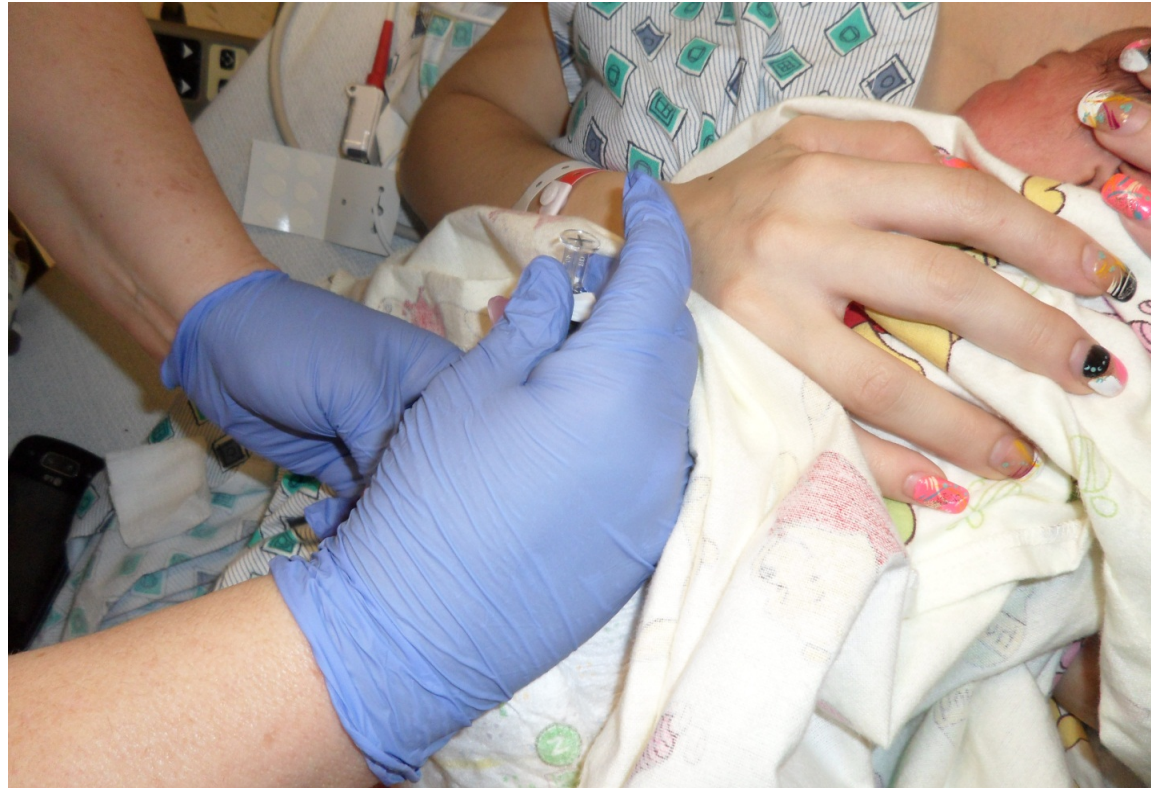

Figure 7. Injection.

formally provided feedback. Use of the procedure delineated above should make use of SSC during painful procedures more consistent than currently occurs [27]. The evidence base clearly supports SSC as an effective pain reduction nursing intervention [16] [26] [38] [39] [40]. The procedure described above meets criteria for maintaining ergonomic integrity of the health care worker conducting the painful procedures. Other studies used an adjustable stool for the care providers to set in to provide them with a comfortable position [28]. In this study, the bed was adjusted to about 60 degrees and the nurse raised the bed up to comfortably reach the newborns' heel and thigh without bending and hurting her back. 
Nurses may need to practice on simulation models how to perform different painful procedures during SSC to facilitate their comfort when performing painful procedures on patients. Nurses may also need to practice the step-bystep procedure a few times with peer support until the procedure becomes automatic. As the SSC intervention becomes more commonplace, its use as a pain reduction strategy will satisfy current requirements to use pain reduction interventions with each and every noxious experience during hospitalization [41]. Having a written policy for the use of SSC with single and clustered pain procedures will enhance practice.

\section{Summary}

SSC is recommended as a non-pharmacological intervention to minimize full term newborn's procedural pain. Using the procedure listed above for lancing and injections during SSC should help eliminate physical discomfort in nurses. For the nurse, the procedure provides a way to support the ergonomically normal position of the spine with its lumbar and cervical curves. The body's line of gravity is sustained in the procedure and kyphosis is avoided; kyphosis causes the discomfort commonly experienced when bending over to complete these care procedures. The hope is that nurses increase their use of SSC in their daily practice.

\section{Conflicts of Interest}

Raouth R. Kostandy reports no financial interest or potential conflicts of interest. Susan M. Ludington-Hoe reports no financial interest or potential conflicts of interest.

\section{Funding}

Financial support for the study was provided in part by The University of Akron, College of Nursing Research Award and The University of Akron Faculty Research Grants and Fellowships and both organizations had no role in execution of the study beyond financial support.

\section{References}

[1] American Academy of Pediatrics (2006) Prevention and Management of Pain in the Neonate: An Update. Pediatrics, 118, 2231-2241.

https://doi.org/10.1542/peds.2006-2277

[2] American Academy of Pediatrics (2007) New Neonatal AAP Pain Management Recommendations. Neonatal Network, 26, 135. https://doi.org/10.1891/0730-0832.26.2.135

[3] Canadian Paediatric Society, Fetus and Newborn Committee (2012) Practice Point. Kangaroo Care for the Preterm Infant and Family. Paediatrics and Child Health, 17, 141-143.

[4] Anand, K.J. and Scalzo, F.M. (2000) Can Adverse Neonatal Experiences Alter Brain Development and Subsequent Behavior? Biology of the Neonate, 77, 69-82. https://doi.org/10.1159/000014197 
[5] Beggs, S. (2015) Long-Term Consequences of Neonatal Injury. Canadian Journal of Psychiatry, 60, 176-180.

[6] Bhutta, A.T. and Anand, K.J. (2002) Vulnerability of the Developing Brain. Neuronal Mechanisms. Clinics in Perinatology, 29, 357-372. https://doi.org/10.1016/S0095-5108(02)00011-8

[7] Anand, K.J.S. (1998) Clinical Importance of Pain and Stress in Preterm Neonates. Biology of the Neonates, 73, 109.

[8] Anand, K.J.S. and Hickey, P.R. (1987) Pain and Its Effects in the Human Neonate and Fetus. The New England Journal of Medicine, 317, 1321-1329. https://doi.org/10.1056/NEJM198711193172105

[9] Taddio, A., Shah, V., Gilbert-MacLeod, C. and Katz, J. (2002) Conditioning and Hyperalgesia in Newborns Exposed to Repeated Heel Lances. The Journal of the American Medical Association, 288, 857-861. https://doi.org/10.1001/jama.288.7.857

[10] Abdulkader, H.M., Freer, Y., Garry, E.M., Fleetwood-Walker, S.M. and McIntosh, N. (2008) Prematurity and Neonatal Noxious Events Exert Lasting Effects on Infant Pain Behavior. Early Human Development, 84, 351-355. https://doi.org/10.1016/j.earlhumdev.2007.09.018

[11] Hermann, C., Hohmeister, J., Demirakça, S., Zohsel, K. and Flor, H. (2006) LongTerm Alteration of Pain Sensitivity in School-Aged Children with Early Pain Experiences. Pain, 125, 278-285. https://doi.org/10.1016/j.pain.2006.08.026

[12] Grunau, R.E., Holsti, L., Haley, D.W., Oberlander, T., Weinberg, J., Solimano, A., Whitfield, M.F., Fitzgerald, C. and Yu, W. (2005) Neonatal Procedural Pain Exposure Predicts Lower Cortisol and Behavioral Reactivity in Preterm Infants in the NICU. Pain, 113, 293-300. https://doi.org/10.1016/j.pain.2004.10.020

[13] Johnston, C.C., Campbell-Yeo, M. and Filion, F. (2011) Paternal vs Maternal Kangaroo Care for Procedural Pain in Preterm Neonates: A Randomized Crossover Trial. Archives of Pediatric and Adolescent Medicine, 165, 792-796. https://doi.org/10.1001/archpediatrics.2011.130

[14] Warnock, F.F., Castral, T.C., Brant, R., Sekilian, M., Leite, A.M., Owens Sde, L. and Scochi, C.G. (2010) Brief Report: Maternal Kangaroo Care for Neonatal Pain Relief: A Systematic Narrative Review. Journal of Pediatric Psychology, 35, 975-984. https://doi.org/10.1093/jpepsy/jsp123

[15] Kashaninia, Z., Sajedi, F., Rahgozar, M. and Noghabi, A. (2008) The Effect of Kangaroo Care on Behavioral Responses to Pain of an Intramuscular Injection in Neonates. Journal for Specialists in Pediatric Nurses, 13, 275-280. https://doi.org/10.1111/j.1744-6155.2008.00165.x

[16] Kostandy, R.R., Anderson, G.C. and Good, M. (2013) Skin-to-Skin Contact Diminishes Pain from Hepatitis B Vaccine Injection in Healthy Full-Term Neonates. Neonatal Network, 32, 274-280. https://doi.org/10.1891/0730-0832.32.4.274

[17] Kostandy, R.R. and Ludington-Hoe, S.M. (2016) Kangaroo Care (Skin-to-Skin) for Clustered Pain Procedures: Case Study. World Journal of Neuroscience, 6, 43-51. https://doi.org/10.4236/wjns.2016.61006

[18] Gray, L., Miller, L.W., Philipp, B.L. and Blass, E.M. (2002) Breastfeeding Is Analgesic in Healthy Newborns. Pediatrics, 109, 590-593.

https://doi.org/10.1542/peds.109.4.590

[19] Chermont, A.G., Falcão, L.F., de Souza Silva, E.H., de Cássia Xavier Balda, R. and Guinsburg, R. (2009) Skin-to-Skin Contact and/or Oral 25\% Dextrose for Procedural Pain Relief for Term Newborn Infants. Pediatrics, 124, e1101-e1107. 
https://doi.org/10.1542/peds.2009-0993

[20] Johnston, C.C., Filion, F., Campbell-Yeo, M., Goulet, C., Bell, L., McNaughton, K. and Byron, J. (2009) Enhanced Kangaroo Mother Care for Heel Lance in Preterm Neonates: A Crossover Trial. Journal of Perinatology, 29, 51-56. https://doi.org/10.1038/jp.2008.113

[21] Bulfone, G., Nazzi, E. and Tenore, A. (2011) Kangaroo Mother Care and Conventional Care: A Review of the Literature. Professioni Infermieristiche, 64, 75-82.

[22] Liu, M., Zhao, L. and Li, X.F. (2015) Effect of Skin Contact between Mother and Child in Pain Relief of Full-Term Newborns during Heel Blood Collection. Clinical and Experimental Obstetrics \& Gynecology, 42, 304-308.

[23] Seo, Y.S., Lee, J. and Ahn, H.Y. (2016) Effects of Kangaroo Care on Neonatal Pain in South Korea. Journal of Tropical Pediatrics, 62, 246-249. https://doi.org/10.1093/tropej/fmv102

[24] Saeidi, R., Asnaashari, Z., Amir Nejad, M., Esmaeili, H. and Robatsangi, M.G. (2011) Use of "Kangaroo Care" to Alleviate the Intensity of Vaccination Pain in Newborns. Iranian Journal of Pediatrics, 21, 99-102.

[25] Dezhdar, S., Jahanpour, F., Firouz Bakht, S. and Ostovar, A. (2016) The Effects of Kangaroo Mother Care and Swaddling on Venipuncture Pain in Premature Neonates: A Randomized Clinical Trial. Iranian Red Crescent Medical Journal, 18, e29649.

[26] Johnston, C.C., Campbell-Yeo, M., Fernandes, A., Inglis, D., Streiner, D. and Zee, R. (2014) Skin-to-Skin Care for Procedural Pain in Neonates. Cochrane Database of Systematic Reviews, Art. No.: CD008435. https://doi.org/10.1002/14651858.cd008435.pub2

[27] Benoit, B., Campbell-Yeo, M., Johnston, C., Latimer, M., Caddell, K. and Orr, T. (2016) Staff Nurse Utilization of Kangaroo Care as an Intervention for Procedural Pain in Preterm Infants. Advances in Neonatal Care, 16, 229-238. https://doi.org/10.1097/ANC.0000000000000262

[28] Cong, X., Ludington-Hoe, S.M., Vazquez, V., Zhang, D. and Zaffetti, S. (2013) Ergonomic Procedure for Heel Sticks and Shots in Kangaroo Care (Skin-to-Skin) Position. Neonatal Network, 32, 353-357. https://doi.org/10.1891/0730-0832.32.5.353

[29] Latimer, M., Jackson, P., Johnston, C. and Vine, J. (2011) Examining Nurse Empathy for Infant Procedural Pain: Testing a New Video Measure. Pain Research and Management, 16, 228-233. https://doi.org/10.1155/2011/198703

[30] Mallet, I., Bomy, H., Govaert, N., Goudal, I., Brasme, C., Dubois, A., Boudringhien, S. and Pierrat, V. (2007) Skin to Skin Contact in Neonatal Care: Knowledge and Expectations of Health Professionals in 2 Neonatal Intensive Care Units. Archives de Pediatrie, 14, 881-886. https://doi.org/10.1016/j.arcped.2007.01.017

[31] Le Huec, J.C., Saddiki, R., Franke, J., Rigal, J. and Aunoble, S. (2011) Equilibrium of the Human Body and the Gravity Line: The Basics. European Spine Journal, 20, 558-563. https://doi.org/10.1007/s00586-011-1939-7

[32] Jang, R., Karwowski, W., Quesada, P.M., Rodrick, D., Sherehiy, B., Cronin, S.N. and Layer, J.K. (2007) Biomechanical Evaluation of Nursing Tasks in a Hospital Setting. Ergonomics, 50, 1835-1855. https://doi.org/10.1080/00140130701674661

[33] Axelin, A., Lehtonen, L., Pelander, T. and Salanterä, S. (2010) Mothers' Different Styles of Involvement in Preterm Infant Pain Care. Journal of Obstetric, Gynecologic, and Neonatal Nursing, 39, 415-424. https://doi.org/10.1111/j.1552-6909.2010.01150.x

[34] Franck, L.S., Oulton, K. and Bruce, E. (2012) Parental Involvement in Neonatal Pain 
Management: An Empirical and Conceptual Update. Journal of Nursing Scholarship, 44, 45-54. https://doi.org/10.1111/j.1547-5069.2011.01434.x

[35] Folk, L.A. (2007) Guide to Capillary Heelstick Blood Sampling in Infants. Advances in Neonatal Care, 7, 171-178. https://doi.org/10.1097/01.ANC.0000286333.67928.04

[36] Gray, L., Watt, L. and Blass, E. (2000) Skin-to-Skin Contact Is Analgesic in Healthy Newborns. Pediatrics, 105, e14-e24. https://doi.org/10.1542/peds.105.1.e14

[37] Marín Gabriel, M.Á., del Rey Hurtado de Mendoza, B., Jiménez Figueroa, L., Medina, V., Iglesias Fernández, B., Vázquez Rodríguez, M., Escudero Huedo, V. and Medina Malagón, L. (2013) Analgesia with Breastfeeding in Addition to Skin-to-Skin Contact during Heel Prick. Archives of Disease in Childhood-Fetal and Neonatal Edition, 98, F499-F503. https://doi.org/10.1136/archdischild-2012-302921

[38] Meek, J. and Huertas, A. (2012) Cochrane Review: Non-Nutritive Sucking, Kangaroo care and Swaddling/Facilitated Tucking Are Observed to Reduce Procedural Pain in Infants and Young Children. Evidence-Based Nursing, 15, 84-85. https://doi.org/10.1136/ebnurs-2011-100453

[39] Pillai Riddell, R., Racine, N., Turcotte, K., Uman, L., Horton, R., Din Osmun, L., Ahola Kohut, S., Hillgrove-Stuart, J., Stevens, B. and Lisi, D. (2011) Nonpharmacological Management of Procedural Pain in Infants and Young Children: An Abridged Cochrane Review. Pain Research and Management, 16, 321-330. https://doi.org/10.1155/2011/489286

[40] Taddio, A., et al. (2015) Reducing Pain during Vaccine Injections: Clinical Practice Guideline. Canadian Medical Association Journal, 187, 975-982. https://doi.org/10.1503/cmaj.150391

[41] Joint Commission (2011) Provision of Care, Treatment, and Services (PC). Available from Joint Commission Resources 877-223-6866, Joint Commission of Accreditation of Health Organizations (JCAHO), Washington DC.

\section{Submit or recommend next manuscript to SCIRP and we will provide best service for you:}

Accepting pre-submission inquiries through Email, Facebook, LinkedIn, Twitter, etc. A wide selection of journals (inclusive of 9 subjects, more than 200 journals)

Providing 24-hour high-quality service

User-friendly online submission system

Fair and swift peer-review system

Efficient typesetting and proofreading procedure

Display of the result of downloads and visits, as well as the number of cited articles

Maximum dissemination of your research work

Submit your manuscript at: http://papersubmission.scirp.org/

Or contactwjns@scirp.org 